\title{
Stage II Ampulla of Vater Cancer AJCC v8
}

National Cancer Institute

\section{Source}

National Cancer Institute. Stage II Ampulla of Vater Cancer A/CC v8. NCI Thesaurus. Code C134869.

Stage II includes: IIA: T3a, N0, M0; IIB: T3b, N0, M0. T3a: Tumor directly invading the pancreas (up to $0.5 \mathrm{~cm}$ ). T3b: T umor extending more than $0.5 \mathrm{~cm}$ into the pancreas, or extending into peripancreatic tissue or duodenal serosa without involvement of the celiac axis or superior mesenteric artery. N0: No regional lymph node metastasis. M0: No distant metastasis. (AJCC 8th ed.) 